\title{
Effects of nicotine, nornicotine and cotinine, alone or in combination, on locomotor activity and ultrasonic vocalization emission in adult rats
}

\author{
Yufei Wang ${ }^{1} \cdot$ Benson Wan ${ }^{1} \cdot$ Jodie Huang ${ }^{1} \cdot$ Paul B. S. Clarke ${ }^{1}$ (D) \\ Received: 7 February 2020 / Accepted: 31 May 2020 / Published online: 18 June 2020 \\ (C) Springer-Verlag GmbH Germany, part of Springer Nature 2020
}

\begin{abstract}
Rationale The behavioral effects of the nicotine metabolites nornicotine and cotinine have not been investigated extensively. Objectives To evaluate the effects of nicotine, cotinine, and nornicotine, given alone or in combination, on locomotor activity and emission of ultrasonic vocalizations in male adult rats.

Methods Rats were first given home cage nicotine injections to make them tolerant to the drug's locomotor depressant effects. On subsequent days, locomotor activity (LMA) and ultrasonic vocalizations were recorded in an open field, for 60 min after challenge injection, using repeated measures designs. In single-drug experiments, subjects were tested with nicotine $0.05-$ $0.4 \mathrm{mg} / \mathrm{kg}$, cotinine $0.03-3 \mathrm{mg} / \mathrm{kg}$, or nornicotine $0.1-10 \mathrm{mg} / \mathrm{kg}$. In drug-combination experiments, saline or nicotine $0.2 \mathrm{mg} / \mathrm{kg}$ challenge was preceded by cotinine $(0,0.3,3 \mathrm{mg} / \mathrm{kg})$ or nornicotine $(0,0.1,0.3,1,3 \mathrm{mg} / \mathrm{kg})$ injection.

Results High doses of nornicotine increased LMA and blunted the locomotor stimulant effect of nicotine. Less consistently, nicotine and high doses of nornicotine decreased the $50-\mathrm{kHz}$ call rate, with no clear evidence of a nornicotine $\times$ nicotine interaction. Cotinine, given alone or before nicotine injection, altered neither LMA nor the call rate. No drug altered the relative prevalence of flat vs. trill 50-kHz call subtypes, except that the highest dose of nornicotine promoted flat calls over trills. No drug evoked 22-kHz calls.

Conclusion Nornicotine can exert an acute anti-nicotine effect in vivo, as previously reported in vitro. The finding that nicotine did not detectably alter the $50-\mathrm{kHz}$ call profile appears consistent with this drug's mild subjective effects in human subjects.
\end{abstract}

Keywords Nicotine $\cdot$ Nornicotine $\cdot$ Cotinine $\cdot$ Ultrasonic vocalization $\cdot$ Locomotion $\cdot$ Rat behavior

\section{Introduction}

Nornicotine is a tobacco constituent and minor metabolite of nicotine, whereas cotinine is a major nicotine metabolite and a commonly used biomarker of smoking status (Hukkanen et al. 2005). Thus, in smokers, less than $1 \%$ of nicotine is metabolized to nornicotine, with a similar amount derived from inhaled tobacco smoke, whereas around $70 \%$ of nicotine is metabolized to cotinine (Benowitz and Jacob, III 1994; Benowitz et al. 1994). Nornicotine and cotinine possess longer elimination half-lives than nicotine (Hukkanen et al. 2005;

Paul B. S. Clarke

paul.clarke@mcgill.ca

1 Department of Pharmacology and Therapeutics, McGill University, McIntyre Medical Building Rm. 1320, 3655 Promenade Sir William Osler, Montreal, QC H3G 1Y6, Canada
Kyerematen et al. 1990b), and rodent studies additionally suggest that both metabolites accumulate in the brain during prolonged exposure to nicotine (Ghosheh et al. 2001). Thus, it has been proposed that both agents may reach pharmacologically relevant concentrations in the brains of smokers (Crooks and Dwoskin 1997; Ghosheh et al. 1999; Ghosheh et al. 2001; Miksys et al. 2000).

Nornicotine and cotinine activate neuronal nicotinic cholinergic receptors (nAChRs), although often only at higher doses than nicotine (Crooks and Dwoskin 1997; Dwoskin et al. 1999b). For example, nornicotine is reported to act less potently than nicotine in evoking neurotransmitter release in vitro (e.g., Dwoskin et al. 1995; Green et al. 2001; Lu et al. 1998), and also in several rodent behavioral assays (Bardo et al. 1999; Dwoskin et al. 1999a; Goldberg et al. 1989; Stolerman et al. 1995; Takada et al. 1989). Nornicotine nevertheless activates certain recombinant nAChR subtypes more potently than nicotine (Papke et al. 
2007). Cotinine typically interacts with $n A C h R$ agonists only at very high concentrations (Briggs and McKenna 1998; Dwoskin et al. 1999b; Terry et al. 2015; Vainio et al. 2000) and has additional, nAChR-independent, actions via molecular targets that remain largely obscure (Buccafusco and Terry 2003; Goldberg et al. 1989; Terry et al. 2015).

Numerous in vitro studies suggest that nornicotine and cotinine can also desensitize CNS nAChRs (Briggs and McKenna 1998; Dwoskin et al. 1999b, 2001; Green et al. 2001; Lu et al. 1999; Oliver et al. 2007; Teng et al. 1997; Terry et al. 2015; Vainio et al. 2000), and in addition, nornicotine has been identified as a partial agonist at certain recombinant nAChR subtypes (Papke et al. 2007). However, nicotine-opposing actions of these compounds have been little investigated in vivo. Notably, acute pretreatment with nornicotine, which did not inhibit the nicotine cue (Caine et al. 2014), suppressed intravenous nicotine self-administration in rodents (Caine et al. 2014; Green et al. 2000; Stairs et al. 2007). However, with regard to the latter finding, it is unclear whether nornicotine substituted for nicotine or directly inhibited nicotine's actions at nAChRs.

A major aim of the present study was therefore to identify possible anti-nicotine effects of nornicotine and cotinine in vivo. The main measure used for this purpose was nicotine-induced stimulation of locomotor activity (LMA). This behavioral effect was chosen because it occurs through a direct activation of brain nAChRs and is stable across repeated testing (Clarke and Kumar 1983a; Clarke and Kumar 1983b; Stolerman et al. 1995). During the locomotor test sessions, we also determined the acute effects of nicotine, nornicotine, and cotinine on the emission of ultrasonic vocalizations (USVs). Adult rats emit two broad classes of USVs: 22-kHz "alarm" calls, and 50-kHz calls (Brudzynski 2015; Wohr and Schwarting 2013). Among the plethora of identifiable 50-kHz call subtypes (Wright et al. 2010), "trill" and "flat" calls are of particular interest. In particular, rewarding drugs, as well as anticipation of play, preferentially promote trill calls over flat calls (Best et al. 2017; Burke et al. 2017; Simola and Brudzynski 2018; Wright et al. 2012b; Wright et al. 2010), whereas acute morphine withdrawal produced the opposite shift (Lin et al. 2018). On this basis, the relative prevalence of trill and flat calls appear to signal positive vs. negative affect.

Based on these considerations, we predicted that nicotine, which is only weakly euphoriant in humans (Dar et al. 2007; Kalman 2002), would, at best, mildly promote trills over flat calls. Previous published studies have not detected such an effect, but low overall rates of calling may have hindered detection (Simola et al. 2012; Simola et al. 2014; Swalve et al. 2019; Swalve et al. 2016). Possible mood-modifying effects of nornicotine have apparently not been studied in human subjects, whereas cotinine appears not to improve mood and may possibly be mildly anxiogenic (Benowitz et al. 1983; Hatsukami et al. 1998; Keenan et al. 1994). Since drug-induced anxiety does not appear to produce a consistent change in USV emission (Willadsen et al. 2018), cotinine would be expected not to affect USV emission, whereas nornicotine would mimic nicotine, albeit less potently, based its nicotine-like activity in other in vitro and behavioral assays (see above). In the present study, we also analyzed the rate of $50-\mathrm{kHz}$ call emission, predicting that since our rats had a history of nicotine exposure, this drug would likely promote 50$\mathrm{kHz}$ calling (Swalve et al. 2016), potentially providing an additional measure with which to assess drug-drug interactions.

The present study therefore sought to address several questions. First, what are the locomotor effects of nornicotine and cotinine, given alone and in combination with nicotine? Second, does acute pretreatment with nornicotine or cotinine blunt acute behavioral effects of nicotine? Lastly, how do these three drugs affect the emission $50-\mathrm{kHz}$ USV subtypes, especially those proposed to reflect affect? To address these questions, we initially tested a range of doses of nicotine, nornicotine and cotinine, each drug given alone. Subsequently, to test the effects of nicotine after acute nornicotine or cotinine pretreatment, we selected a dose of nicotine $(0.2 \mathrm{mg} / \mathrm{kg})$ that produced robust locomotor stimulation. In these drug-combination experiments, we included nornicotine and cotinine doses that appeared behaviorally inactive, since nicotinic agonists tend to desensitize nAChRs even at concentrations lower than required for activation (Rollema and Hurst 2018).

\section{Methods}

\section{Animals}

Subjects were adult male Long-Evans rats (Charles River Laboratories, Kingston, NY, USA). At the start of testing, body weights were as follows (for experiments 1-6, respectively): 242-303, 275-290, 265-320, $265-311,240-263$, and $410-540 \mathrm{~g}$. The rats were housed two per cage in a humidity- and temperaturecontrolled colony room at the McGill University Animal Resources Center. Home cage bedding consisted of laboratory-grade Beta Chip ${ }^{\circledR}$ (NEPCO, Warrensburg, NY). Rats were maintained on a reverse 12:12-h light/ dark cycle with the lights off at $0700 \mathrm{~h}$, and all testing was performed during the dark phase of the cycle. Food and water were available ad libitum except during testing. All procedures were approved by the McGill Animal Care Committee in accordance with the guidelines of the Canadian Council on Animal Care. 


\section{Drugs}

The following drugs were used: (S)-(-)-nicotine hydrogen ditartrate (Sigma-Aldrich, ON, Canada), (R,S)- $( \pm)$ nornicotine and (S)-(-)-cotinine (catalog numbers N757000 and $\mathrm{C} 725000$, both of $98 \%$ purity, from Toronto Research Chemicals, ON, Canada). All drugs were dissolved in $0.9 \%$ sterile saline. Nicotine and nornicotine solutions were $\mathrm{pH}-$ neutralized with dilute $\mathrm{NaOH}$, to $\mathrm{pH} 7.2 \pm 0.2$ and $\mathrm{pH} 6.8-$ 7.3 , respectively. Injections were given subcutaneously (SC) into the flank in a volume of $1 \mathrm{ml} / \mathrm{kg}$. Control injections were of saline. Nicotine doses are expressed as base.

The choice of racemic nornicotine and the (S)-(-)- stereoisomer of cotinine was based on the following considerations. Both nornicotine enantiomers are present in tobacco smoke, with the (S)-isomer being more prevalent (Liu et al. 2008). Nornicotine is also formed from nicotine, both in the periphery and potentially to a significant extent in the brain (Crooks et al. 1997; Ghosheh et al. 2001). This N-demethylation step has been shown to favor the $(\mathrm{R})-(+)$-nornicotine enantiomer in hamsters (Kyerematen et al. 1990a), but whether this is the case in rats or humans appears uninvestigated. With regard to cotinine, the (S)-(-)- isomer appears to predominate in cigarette smokers, since nicotine metabolism is generally stereospecific (Kyerematen and Vesell 1991) and since tobacco smoke contains mainly the (S)-(-)- isomer of nicotine (Hukkanen et al. 2005).

\section{Testing boxes and locomotor activity}

Four rectangular test boxes were used $(58 \mathrm{~cm}$ long, $29 \mathrm{~cm}$ wide, and $53 \mathrm{~cm}$ high). Each comprised four vertical wooden white-painted walls, covered by an 8-mm-thick clear Plexiglas ${ }^{\mathrm{TM}}$ lid, attached by a hinge. The four test boxes were placed in a quadrant configuration, $2.5 \mathrm{~cm}$ apart, on a layer of Beta Chip ${ }^{\circledR}$ bedding which was changed between experiments but not between individual sessions. The boxes were lit with Kodak GBX-2 safelight filters (Vistek, Toronto, Ontario, Canada) providing far-red (wavelength $>650 \mathrm{~nm}$ ) illumination. A video camera (WV-BP330 CCTV, Panasonic, USA) was positioned overhead, and software (MediaCruise, Canopus Corp., San Jose, CA, USA) created an MPEG video file of each session. The video recording was tracked offline using the EthoVision v. 3.0 software (Noldus Information Technology, Leesburg, VA, USA) in order to measure locomotor activity (LMA, i.e., total horizontal distance moved).

\section{Acquisition and acoustic analysis of ultrasonic vocalizations}

Broadband recordings and acoustic analysis were performed as detailed in our recent publications (e.g., Best et al. 2017), but adapted to our locomotor test boxes. Thus, each box was equipped with an ultrasonic condenser microphone (CM16/CMPA, Avisoft Bioacoustics, Berlin, Germany), inserted through a small $(9 \mathrm{~cm} \times 6 \mathrm{~cm})$ recess cut halfway along one long side of the lid, and connected to an UltraSoundGate $416 \mathrm{H}$ data acquisition device (Avisoft Bioacoustics). The sampling rate was $250-\mathrm{kHz}$ with 16 -bit resolution. Spectrograms were generated by fast Fourier transform (512 points, $75 \%$ overlap, FlatTop window, $100 \%$ frame size) using Avisoft SASLab Pro (v. 5.2.09). All calls in a given session were manually selected from spectrograms by a single individual who was blinded to the treatment conditions. All calls were analyzed, except in experiments 4 and 5 , where a few rats with unusually high call rates (i.e., $>1200$ calls $/ \mathrm{h}$ ) were time-sampled; for these subjects, only calls emitted in every fifth minute were analyzed (i.e., minutes 3,8 , 13, etc.). $22-\mathrm{kHz}$ calls were counted, and $50-\mathrm{kHz}$ calls were categorized according to our 14-subtype scheme (Wright et al. 2010), as indicated in the Fig. 2 legend (below).

\section{General testing procedure (all experiments)}

The rats were initially naïve to drugs and to the experimental apparatus. They were handled once daily for $5 \mathrm{~min}$ for 3 days, and then, on 3 consecutive days, they received twice-daily home cage injections of nicotine $(0.4 \mathrm{mg} / \mathrm{kg} \mathrm{SC}$, at least $10 \mathrm{~h}$ apart). This regimen served to produce tolerance to nicotine's initial locomotor depressant effect, revealing a stronger stimulant effect (Louis and Clarke 1998). On the next day, rats were individually habituated to their test boxes for $15 \mathrm{~min}$. A given rat was always exposed to the same test box throughout each experiment. The first test day followed $24 \mathrm{~h}$ later. On each test day, rats were transported from the colony room, weighed, and left in their home cages for $15 \mathrm{~min}$ to habituate. In some experiments (see Table 1), rats were tested immediately after a single injection of drug, whereas in other experiments subjects received a pretreatment injection and were returned to their home cage for $30 \mathrm{~min}$, prior to acute challenge with nicotine $(0.2 \mathrm{mg} / \mathrm{kg} \mathrm{SC})$ or saline. Immediately after the acute challenge injection, LMA and USVs were recorded for $60 \mathrm{~min}$. The order of drug presentations was counterbalanced as far as possible within each experiment, based on a modified Williams square.

The timing of drug injections and test days is justified as follows. The 30-min interval between pretreatment-challenge injections was chosen because: (1) cotinine is reported to peak in the brain 30-60 min after SC cotinine injection (Crooks et al. 1997), (2) although the rate of brain entry after SC nornicotine injection has not apparently been reported, behavioral effects are evident within 10-20 min when nornicotine is administered at relevant doses (Dwoskin et al. 1999a; Goldberg et al. 1989; Green et al. 2002; Stairs et al. 2007; Stolerman et al. 1995). The spacing of test days took account 
of the respective brain half-lives reported for nicotine, cotinine, and nornicotine in adult rats, i.e., 52, 333, and $166 \mathrm{~min}$ (Ghosheh et al. 1999). Accordingly, cotinine was tested at 23-day intervals whereas nicotine and nornicotine were both tested at 1-2-day intervals.

\section{Statistical analysis}

Drug solutions were coded so that experimenters were blind to drug conditions. Data were analyzed using Systat software (v. 11, SPSS, Chicago, IL) and figures were generated using Prism 4 (GraphPad Software, La Jolla, CA). Primary measures of interest were locomotor activity (LMA, i.e., horizontal distance traveled), the $50-\mathrm{kHz}$ call rate, and the percentages of flat and trill calls. $50-\mathrm{kHz}$ call profiles were defined by the proportional contributions of all 14 call subtypes (Wright et al. 2010). Data were averaged between any test sessions performed under the same drug conditions, in which case each call (rather than each session) was given equal weight in the call profile calculation. For statistical analysis, call profiles were considered unreliable in test sessions yielding less than 5 calls (i.e., in 33 out of the 500 sessions). In such cases, values for the percent flat and trill prevalence were set as missing, except that in experiments 1-3 (dose-response), these values were interpolated from the two nearest-dose values, and the error degrees of freedom were reduced accordingly. Parametric tests were used unless underlying assumptions were violated. ANOVA factors were all within-subject, as follows: DOSE (i.e., all doses including saline), NIC (nicotine), COT (cotinine), NOR (nornicotine), and TIME (5-min time bins). Fifty-kilohertz call rates were positively skewed and hence analyzed using non-parametric tests (i.e., Friedman or Wilcoxon rank-sum). In experiment 1 , two rats each received an incorrect nicotine dose on one occasion, and data for these sessions was interpolated from adjacent doses. No adjustment was made for multiple comparisons, but instead, the alpha level was set at $1 \%$ (two-tailed) throughout.

\section{Results}

The main findings of all experiments are summarized in Table 2. In all six experiments, $50-\mathrm{kHz}$ calls were much more prevalent than $22-\mathrm{kHz}$ calls. Thus, the total number of $22-\mathrm{kHz}$ and $50-\mathrm{kHz}$ calls emitted in experiments $1-6$ were, respectively: 1672 and 16,979; 205 and 16,795; 229 and 12,602; 47 and $7253 ; 3033$ and 13,$805 ; 277$ and 16,260. The $22-\mathrm{kHz}$ calls were emitted in only a minority of rats and in only a subset of test sessions within a given experiment. Thus, for experiments $1-6$, the number of test sessions containing any $22-\mathrm{kHz}$ calls was, respectively: 10/72, 3/96, 8/96, 3/72, 21/96, and 7/80. There was no clear relation between drug condition and 22-
$\mathrm{kHz}$ USV emission, hence 22-kHz call data are not presented further.

\section{Experiment 1: Nicotine dose-response}

LMA Nicotine dose-dependently stimulated LMA and this effect was not detectably time-dependent (Fig. 1a, b; DOSE $\mathrm{F}_{4,44}=10.47, p=0.0000 ;$ DOSE $\times$ TIME $\mathrm{F}_{44,484}=1.39, p=$ $0.1429)$. Significant increases occurred at doses of $0.1,0.2$, and $0.4 \mathrm{mg} / \mathrm{kg}$ ( $t$ tests, respectively: $t_{11}=3.16, p=0.0091$; $t_{11}=4.97, p=0.0004 ; t_{11}=6.80, \mathrm{p}=0.0000$ ).

50-kHz USVs Nicotine tended to reduce the $50-\mathrm{kHz}$ call rate, but not significantly (Friedman $\mathrm{Q}_{4}=9.20, p=0.0563$ ), even at the three highest doses (Wilcoxon tests: $p=0.0229-0.0281$ ). Median (IQR) 50-kHz calls per session were as follows (for 0 , $0.05,0.1,0.2$ and $0.4 \mathrm{mg} / \mathrm{kg}$, respectively): 260 (155-387), 240 (24-329), 54 (19-98), 68 (3-157), and 61 (18-111). Nicotine also did not significantly alter the percentage of flat calls or trill calls (Fig. 2a-e: DOSE main effects, respectively: $\mathrm{F}_{4,40}=0.46, p=0.7655 ; \mathrm{F}_{4,40}=0.81, p=0.4785$ ).

\section{Experiment 2: Cotinine dose-response}

LMA Cotinine (tested at $0.03-3 \mathrm{mg} / \mathrm{kg}$ ) did not significantly alter LMA (Fig. 1c, d; DOSE $\mathrm{F}_{5,55}=1.25, p=0.2992$; DOSE $\times$ TIME $\left.\mathrm{F}_{55,605}=1.06, p=0.3800\right)$. In contrast, nicotine $(0.2 \mathrm{mg} / \mathrm{kg}$, positive control) increased this measure by approximately $35 \%\left(t_{11}=4.88, p=0.0005\right)$.

50-kHz USVs The call rate was not significantly altered by cotinine (Friedman $Q_{5}=1.64, p=0.8960$ ), but was reduced by nicotine (Wilcoxon $Z=2.98, p=0.0029$ ). Median (IQR) call rates were as follows (saline, cotinine $0.03-3 \mathrm{mg} / \mathrm{kg}$, and nicotine $0.2 \mathrm{mg} / \mathrm{kg}$, respectively): 50 (14-172), 51 (19163), 54 (29-139), 62 (16-135), 61 (25-110), 30 (4-198) and 5 (3-19) calls/60 min. The corresponding call profiles are shown in Fig. $2 \mathrm{f}-1$. Neither cotinine nor nicotine detectably changed the percentage of flat or trill calls (respectively: for cotinine, Friedman $Q_{5}=6.62, p=0.2502$ and $Q_{5}=2.18, p=$ 0.8237 ; for nicotine, Wilcoxon $Z=0.52, p=0.6002$ and $Z=$ $0.34, p=0.7353)$.

\section{Experiment 3: Nornicotine dose-response}

LMA Nicotine $(0.2 \mathrm{mg} / \mathrm{kg})$ increased LMA, as expected $\left(t_{11}=\right.$ $4.01, p=0.0021$ ). Nornicotine (tested at $0.1-10 \mathrm{mg} / \mathrm{kg}$ ) exerted dose- and time-dependent effects on LMA, as shown in Fig. 1e, $\mathrm{f}\left(\mathrm{DOSE} \mathrm{F}_{5,55}=5.89, p=0.0004\right.$; DOSE $\times$ TIME $\left.\mathrm{F}_{55,605}=2.19, p=0.0000\right)$. Nornicotine significantly increased whole-session LMA only at $3 \mathrm{mg} / \mathrm{kg}\left(t_{11}=3.18, p=\right.$ 0.0087 ), and this stimulant effect was apparent from 15 to $50 \mathrm{~min}$ (Fig. 1f). The highest dose of nornicotine $(10 \mathrm{mg} / \mathrm{kg})$, 
Table 1 Summary of experimental conditions

\begin{tabular}{|c|c|c|c|c|c|}
\hline \multirow{2}{*}{$\begin{array}{l}\text { Experiment } \\
1\end{array}$} & \multirow{2}{*}{$\begin{array}{l}n \\
12\end{array}$} & \multicolumn{2}{|c|}{ Pretreatment $(\mathrm{mg} / \mathrm{kg})$} & \multicolumn{2}{|c|}{ Challenge (mg/kg) } \\
\hline & & & & NIC & 0 (twice), $0.05,0.1,0.2,0.4$ \\
\hline \multirow[t]{2}{*}{2} & 12 & & & COT & 0 (twice), $0.03,0.1,0.3,1,3$ \\
\hline & & & & NIC & 0.2 \\
\hline \multirow[t]{2}{*}{3} & 12 & & & NOR & 0 (twice), $0.1,0.3,1,3,10$ \\
\hline & & & & NIC & 0.2 \\
\hline 4 & 12 & COT & $0,0.3,3$ & NIC & $0,0.2$ \\
\hline 5 & 12 & NOR & $0,0.1,0.3,1$ & NIC & $0,0.2$ \\
\hline 6 & 10 & NOR & $0,0.3,1,3$ & NIC & $0,0.2$ \\
\hline
\end{tabular}

NIC, nicotine; $N O R$, nornicotine; COT, cotinine while not significantly altering whole-session LMA, appeared to inhibit LMA in the first 15 min of the session (Fig. 1f).

50-kHz USVs The call rate was significantly reduced by the two highest doses of nornicotine ( 3 and $10 \mathrm{mg} / \mathrm{kg}$ ) and also by nicotine (respectively: Wilcoxon $Z=2.90,2.82$, and 3.06, $p=0.0037,0.0047$ and 0.0022 ). Median (IQR) call rates (i.e., calls/60-min session) were as follows (saline, nornicotine $0.1-$ $10 \mathrm{mg} / \mathrm{kg}$, and nicotine $0.2 \mathrm{mg} / \mathrm{kg}$, respectively): 102 (35155), 97 (11-251), 55 (17-183), 35 (11-164), 17 (9-65), 26 (12-58), and 20 (3-60). Call profiles are shown in Fig. $2 \mathrm{~m}-\mathrm{s}$. Nornicotine altered the call profile only at the highest dose (10 mg/kg, Fig. 2r), significantly increasing the percentage of flats $\left(t_{9}=3.36, p=0.0084\right)$ and tending to inhibit trills $\left(t_{9}=3.10, p=0.0128\right)$. Nicotine affected neither flat or trill call prevalence (respectively: $t_{6}=0.16, p=0.8767 ; t_{6}=0.94$, $p=0.3852$; Fig. 2s).

\section{Experiment 4: Cotinine combined with nicotine}

LMA The locomotor stimulant effect of nicotine (Fig. 3a-c) was not altered by cotinine pretreatment $(\mathrm{COT} \times \mathrm{NIC}$ $\left.\mathrm{F}_{2,22}=2.17, p=0.1381\right)$, irrespective of time within session (3-way interaction $\mathrm{F}_{22,242}=0.92, p=0.5378$ ). Cotinine, given alone, tended to increase LMA at the lower dose (Fig. 3a, $\left.0.3 \mathrm{mg} / \mathrm{kg}: t_{11}=3.06, p=0.0108\right)$.

50-kHz USVs Results are shown in Table 3. Nicotine did not detectably reduce the call rate when it was given alone (Wilcoxon test: $Z=1.18, p=0.2393$ ), but it did significantly decrease this measure when the data were pooled across pretreatment conditions (Wilcoxon test: $Z=3.06, p=0.0022$ ). Cotinine had no overall effect on call rate (Friedman $Q_{2}=$ $1.17, p=0.5580$ ), and did not significantly alter the depressant effect of nicotine, as analyzed by nicotine-saline difference

Table 2 Summary of main findings

\begin{tabular}{|c|c|c|c|c|c|}
\hline Experiment & Drug/doses (mg/kg) & Locomotor activity & $50-\mathrm{kHz}$ call rate & Percent flat & Percent trill \\
\hline 1 & NIC $0,0.05,0.1,0.2,0.4$ & $\uparrow$ at $0.1,0.2$ and $0.4 \mathrm{mg} / \mathrm{kg}$ & $\downarrow ?$ at $0.1,0.2$ and $0.4 \mathrm{mg} / \mathrm{kg}$ & $\leftrightarrow$ & $\leftrightarrow$ \\
\hline 2 & COT $0,0.03,0.1,0.3,1,3$ & $\leftrightarrow$ & $\leftrightarrow$ & $\leftrightarrow$ & $\leftrightarrow$ \\
\hline 2 & NIC 0.2 & $\uparrow$ & $\downarrow$ & $\leftrightarrow$ & $\leftrightarrow$ \\
\hline 3 & NOR $0,0.1,0.3,1,3$, and 10 & $\uparrow$ at $3 \mathrm{mg} / \mathrm{kg}$ & $\downarrow$ at 3 and $10 \mathrm{mg} / \mathrm{kg}$ & $\uparrow$ at $10 \mathrm{mg} / \mathrm{kg}$ & $\downarrow ?$ at $10 \mathrm{mg} / \mathrm{kg}$ \\
\hline 3 & NIC 0.2 & $\uparrow$ & $\downarrow$ & $\leftrightarrow$ & $\leftrightarrow$ \\
\hline 4 & COT $0,0.3$, or 3 & $\uparrow ?$ at $0.3 \mathrm{mg} / \mathrm{kg}$ & $\leftrightarrow$ & $\leftrightarrow$ & $\leftrightarrow$ \\
\hline 4 & NIC 0.2 & $\uparrow$ & $\downarrow$ & $\leftrightarrow$ & $\leftrightarrow$ \\
\hline 4 & $\mathrm{COT} \times \mathrm{NIC}$ & No interaction & No interaction & No interaction & No interaction \\
\hline 5 & NOR $0,0.1,0.3,1$ & $\uparrow$ at $1 \mathrm{mg} / \mathrm{kg}$ & $\leftrightarrow$ & $\leftrightarrow$ & $\leftrightarrow$ \\
\hline 5 & NIC 0.2 & $\uparrow$ & $\downarrow ?$ & $\leftrightarrow$ & $\leftrightarrow$ \\
\hline 5 & $\mathrm{NOR} \times \mathrm{NIC}$ & $\begin{array}{l}\text { Significant at NOR } 1 \mathrm{mg} / \mathrm{kg} \text {, } \\
\text { trend at NOR } 0.3 \mathrm{mg} / \mathrm{kg}\end{array}$ & Interaction? & $\leftrightarrow$ & $\leftrightarrow$ \\
\hline 6 & NOR $0,0.3,1,3$ & $\uparrow$ at $3 \mathrm{mg} / \mathrm{kg}$ & $\leftrightarrow$ & Not analyzed & Not analyzed \\
\hline 6 & NIC 0.2 & $\uparrow$ & $\leftrightarrow$ & Not analyzed & Not analyzed \\
\hline 6 & $\mathrm{NOR} \times \mathrm{NIC}$ & Significant at NOR $3 \mathrm{mg} / \mathrm{kg}$ & No interaction & Not analyzed & Not analyzed \\
\hline
\end{tabular}

The significance level (i.e., alpha) was set at $1 \%$. Arrows refer to effects of drugs when given alone: $\uparrow$ significant increase, $\downarrow$ significant decrease, $\leftrightarrow$ no significant effect. Trends refer to $p=0.05-0.01$, and are shown by "?" (i.e., $\uparrow$ ?, $\downarrow$ ?). COT, cotinine; NIC, nicotine; NOR, nornicotine. Overall, the emission of $22-\mathrm{kHz}$ calls was sporadic, with no clear relation to drug condition; these data are presented briefly at the start of the "Results" section 
scores (Friedman $Q_{2}=3.17, p=0.2053$ ). Neither nicotine nor cotinine, given alone or in combination, appeared to alter the percentage of flat or trill calls (Table $3 ; p>0.05$ for all comparisons).

\section{Experiment 5: Nornicotine combined with nicotine}

LMA The stimulant effect of nicotine, and its interaction with nornicotine, appeared time-dependent (Fig. 3e, f; NIC $\times$ TIME $\mathrm{F}_{11,121}=3.97, p=0.0003$; 3-way interaction $\mathrm{F}_{33,363}=$ $1.50, p=0.0458)$. Nicotine, given alone, did not detectably increase LMA in the second half of the session (Fig. 3e, 30-
60 min: $\left.t_{11}=1.48, p=0.1679\right)$, hence only the $0-30 \mathrm{~min}$ time interval was analyzed further. During this $0-30 \mathrm{~min}$ period (Fig. 3d), the highest nornicotine dose $(1 \mathrm{mg} / \mathrm{kg})$ increased LMA when given alone ( $38 \%$ increase: $t_{11}=4.10, p=$ $0.0018)$. In addition, nornicotine dose-dependently inhibited the locomotor stimulant effect of nicotine (NOR $\times$ NIC $\left.\mathrm{F}_{3,33}=4.77, p=0.0090\right)$. This antagonistic effect was significant at the highest nornicotine dose of $1 \mathrm{mg} / \mathrm{kg}$ (NOR $\times$ NIC $\left.\mathrm{F}_{1,11}=17.00, p=0.0017\right)$, with a similar trend at $0.3 \mathrm{mg} / \mathrm{kg}$ $\left(\mathrm{F}_{1,11}=7.54, p=0.0190\right)$. However, nicotine still tended to increase LMA even after pretreatment with the highest dose of nornicotine $\left(t_{11}=2.24, p=0.0469\right)$.
Fig. 1 Locomotor activity as a function of dose of nicotine, cotinine or nornicotine (experiments 1,2, and 3, respectively). The mean \pm SEM distance moved $(\mathrm{cm})$ is shown for the entire 60-min session (panels $\mathbf{a}, \mathbf{c}$, and $\mathbf{e}$ ), and in consecutive 5-min time bins (panels $\mathbf{b}, \mathbf{d}$, and f). Within each experiment, each rat $(n=12)$ was tested under all conditions. For clarity, some SEM bars are omitted from the time course panels, and lower doses of cotinine and nornicotine are omitted in panels $\mathbf{d}$ and $\mathbf{f}$, respectively. Asterisks are shown only for the whole-session data. ${ }^{*} p<0.05$ (i.e., trend), $* * p<0.01$, $* * * p<0.001$ vs. saline (paired $t$ tests, 2-tailed alpha set at $1 \%$ ) a

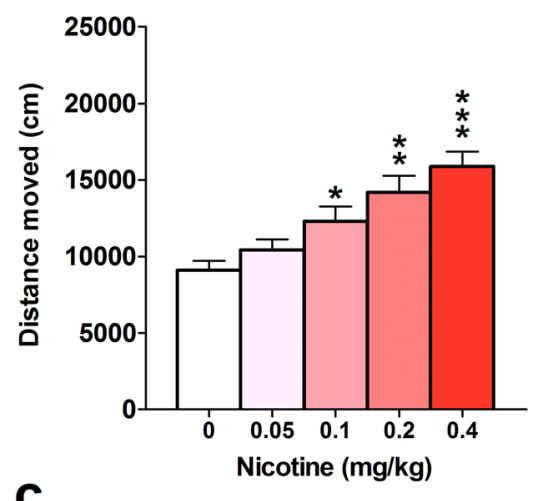

C
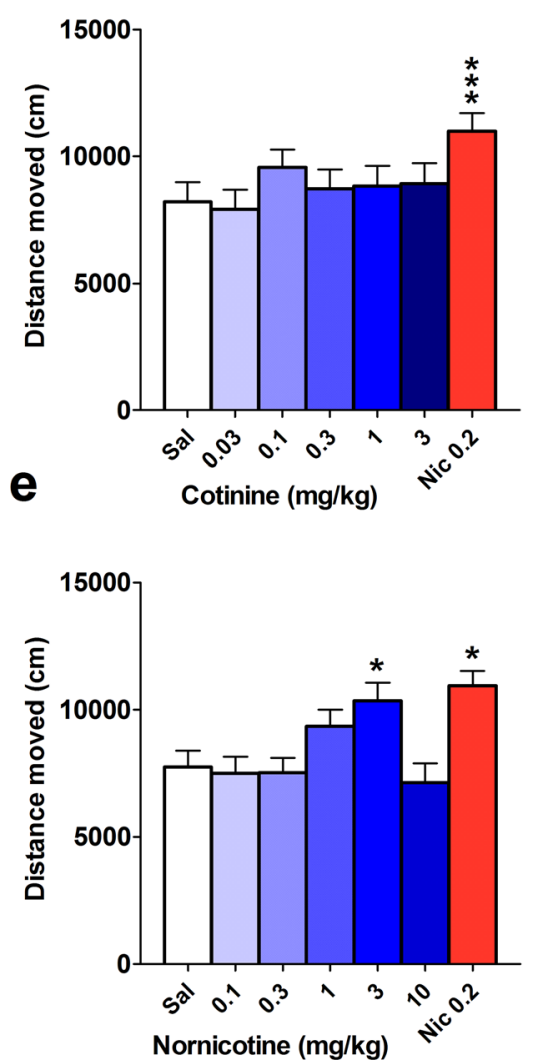

b
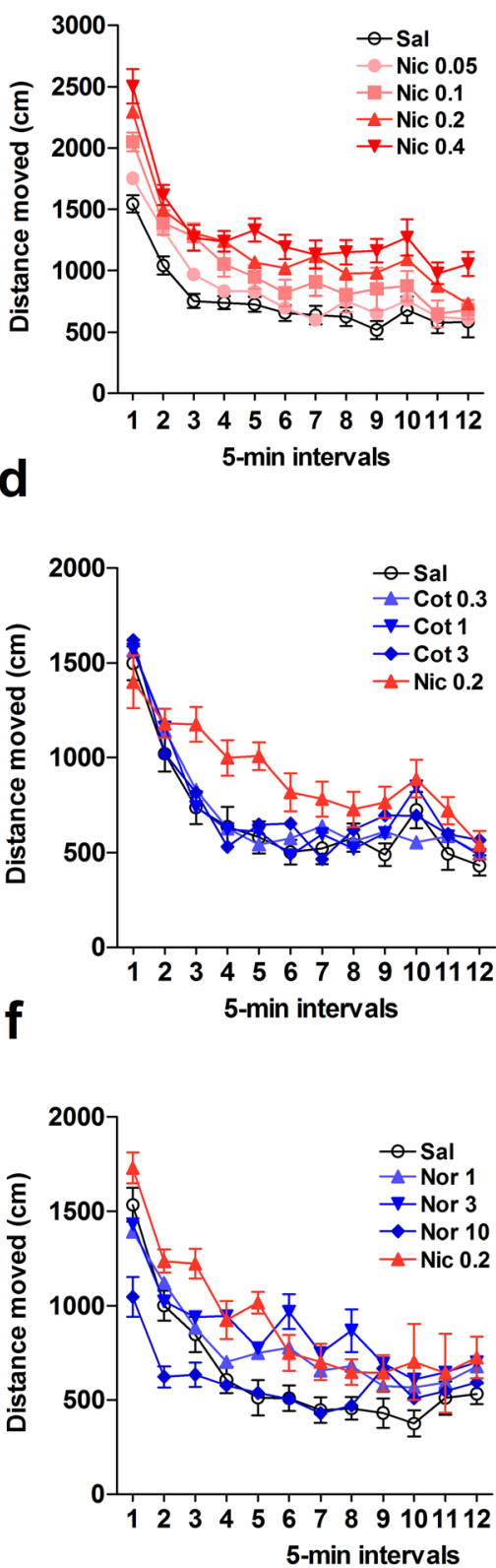
50-kHz USVs When tested alone, nornicotine $(0.1-1 \mathrm{mg} / \mathrm{kg})$ did not discernably alter the $50-\mathrm{kHz}$ call rate (Table 3 ; Friedman $\left.Q_{3}=0.1000, p=0.9918\right)$. Nicotine $(0.2 \mathrm{mg} / \mathrm{kg})$ tended to reduce the $50-\mathrm{kHz}$ call rate when given alone (Wilcoxon $Z=2.27, p=0.0229$ ), but tended to increase this measure when combined with the higher doses of nornicotine (Table 3). To further assess the possibility of a nornicotine $x$ nicotine interaction, a one-way ANOVA was performed on nicotine-saline difference scores, revealing a non-significant trend $\left(\mathrm{F}_{3,33}=3.80, p=0.0192\right)$.

\section{Experiment 1 Nicotine}

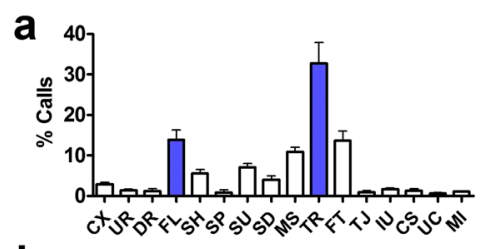

b

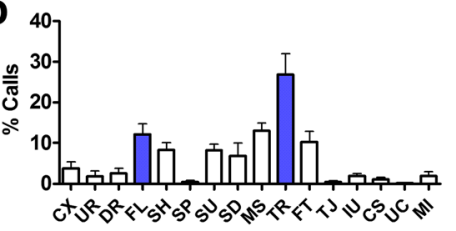

C
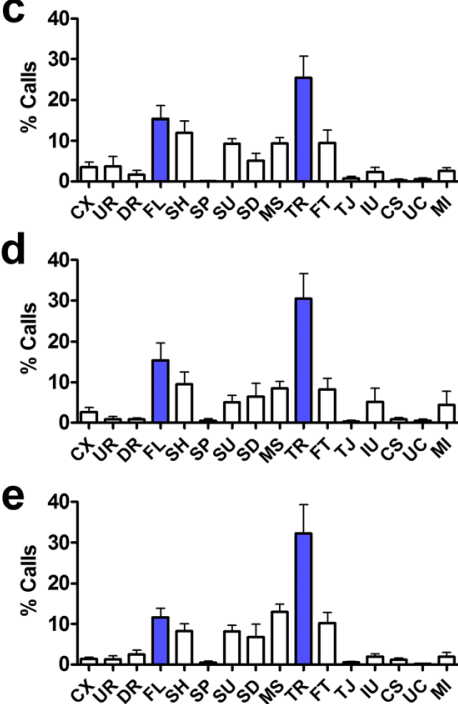

Experiment 2 Cotinine
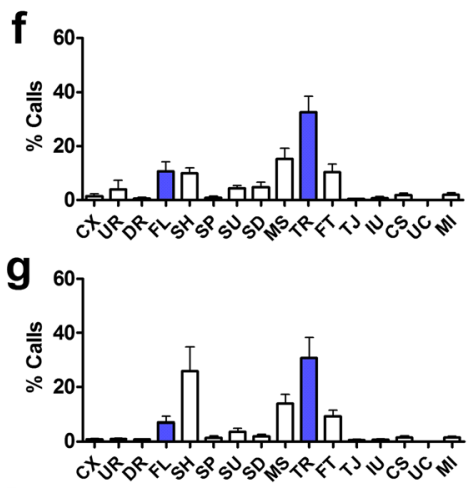

$\mathbf{h}$

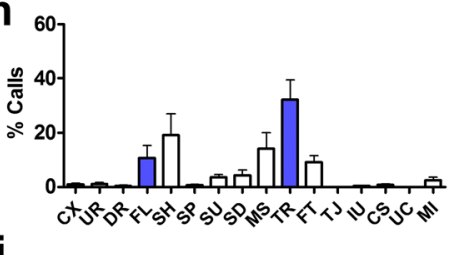

i
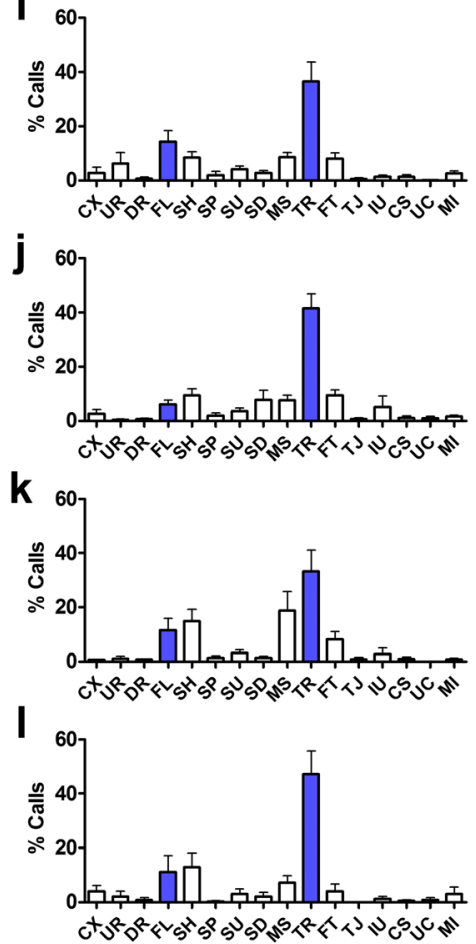

\section{Experiment 3 Nornicotine}

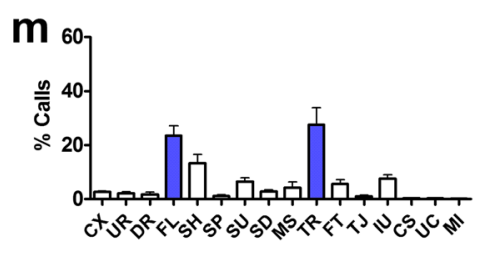

n

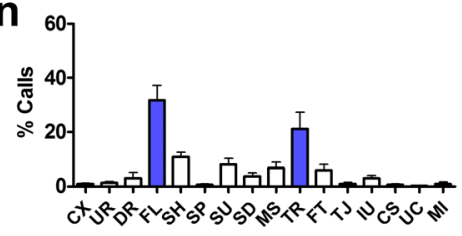

$\mathbf{0}$
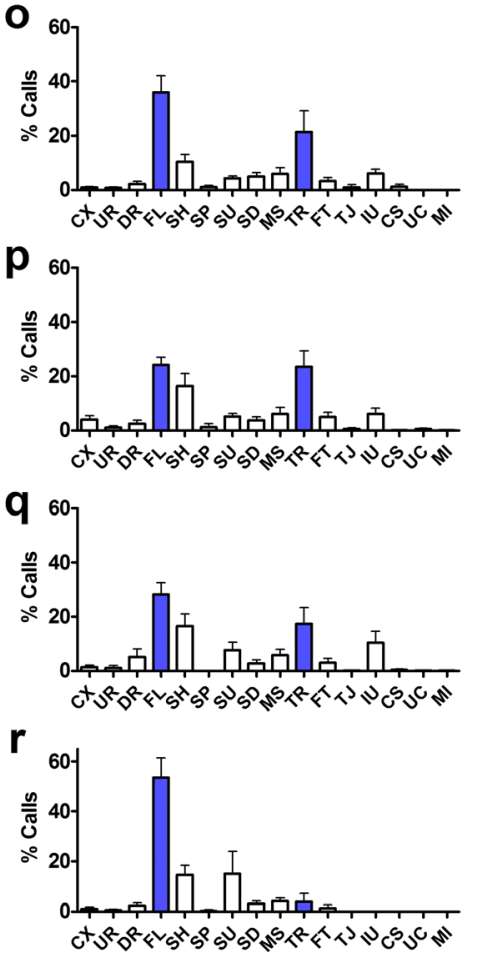

$\mathbf{s}$

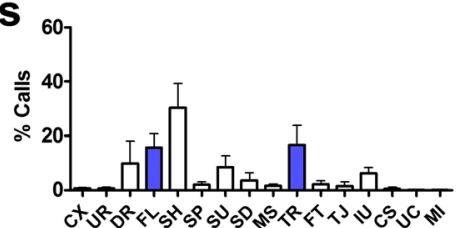

Fig. $250-\mathrm{kHz}$ call subtype profiles: nicotine, cotinine, and nornicotine (experiments 1,2 , and 3 , respectively). Panels a-e represent nicotine $(0$, $0.05,0.1,0.2$, and $0.4 \mathrm{mg} / \mathrm{kg}$, respectively). Panels $\mathbf{f}-\mathbf{I}$ show, respectively, cotinine $0,0.03,0.1,0.3,1$, and $3 \mathrm{mg} / \mathrm{kg}$ and nicotine $0.2 \mathrm{mg} / \mathrm{kg}$. Panels $\mathbf{m}-\mathbf{s}$ show, respectively, nornicotine $0,0.1,0.3,1,3$, and $10 \mathrm{mg} / \mathrm{kg}$ and nicotine $0.2 \mathrm{mg} / \mathrm{kg}$. $Y$-axes show the relative prevalence of each call subtype expressed as the mean \pm SEM percentage of all $50-\mathrm{kHz}$ calls.
Flat (FL) and trill (TR) call data are shown by blue bars. Call subtype abbreviations: CX complex, UR upward ramp, DR downward ramp, FL flat, SH short, SP split, SU step-up, SD step-down, MS multi- step, TR trill, FT flat-trill, TJ trill with jumps, IU inverted-U, CS composite, UC unclear, MI miscellaneous. Within a given experiment, each rat $(n=12)$ was tested under all conditions 
Expt 4 Cotinine

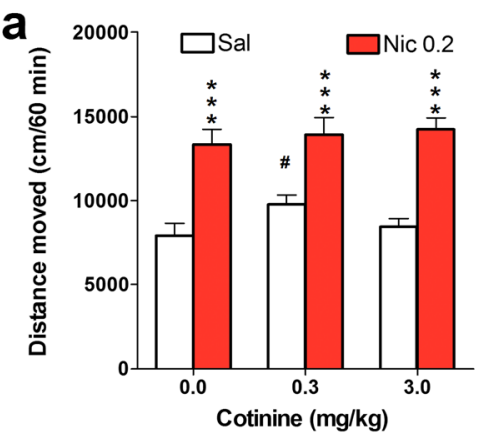

b

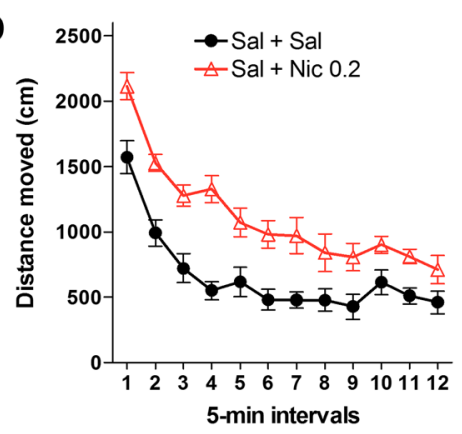

C

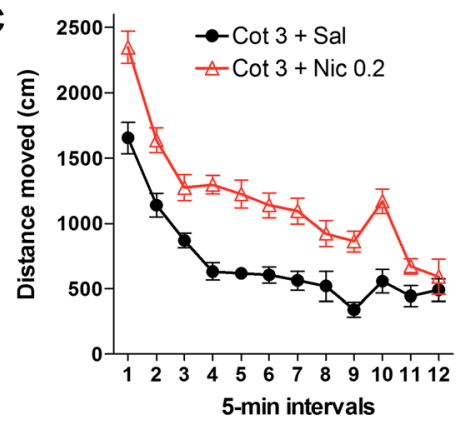

Expt 5 Nornicotine

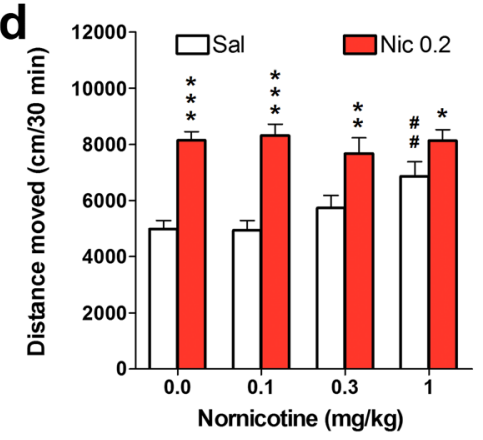

e

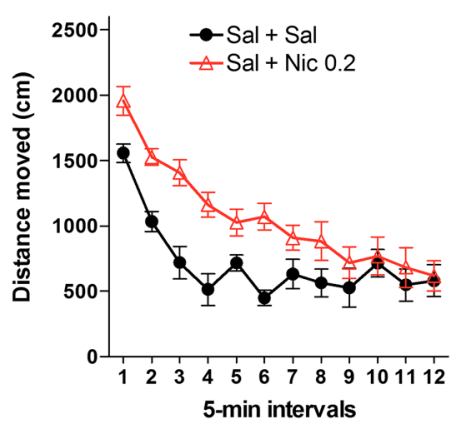

$\mathbf{f}$

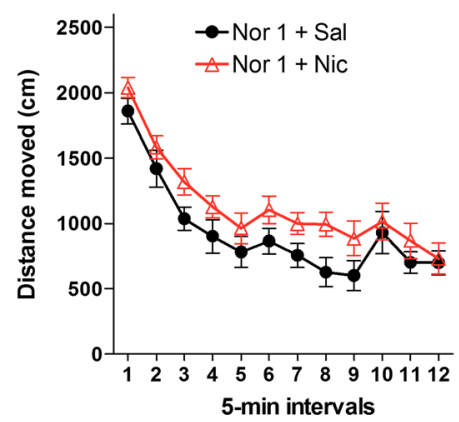

Expt 6 Nornicotine

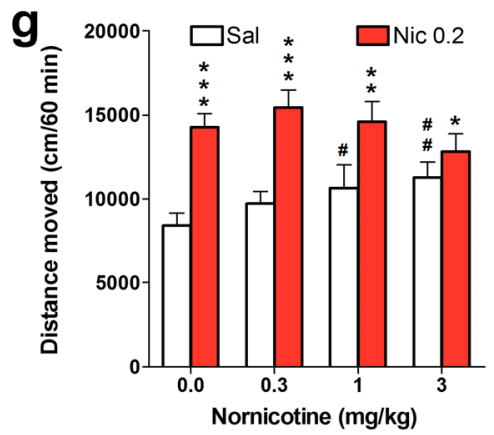

h

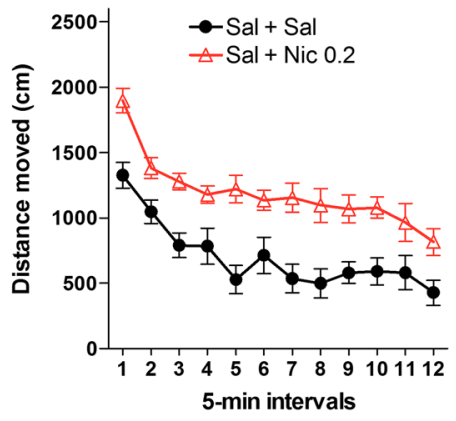

i

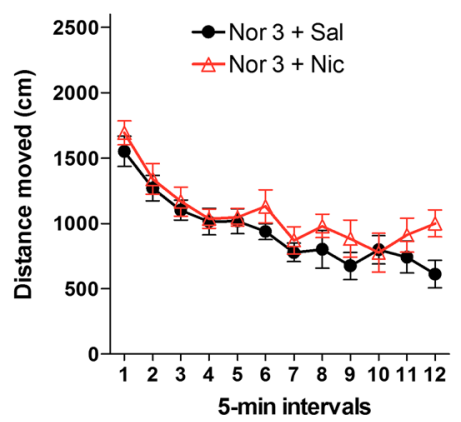

Fig. 3 Nicotine-induced locomotor activity after pretreatment with cotinine (left: experiment 4) or nornicotine (middle and right, respectively: experiments 5 and 6). The top panels show the distance moved across the entire 60-min session (panels $\mathbf{a}$ and $\mathbf{g}$ ) or in the first $30 \mathrm{~min}$ (panel d). The remaining panels illustrate the time course following acute challenge with saline or nicotine $0.2 \mathrm{mg} / \mathrm{kg}$, after pretreatment either with saline (panels $\mathbf{b}, \mathbf{e}, \mathbf{h}$ ) or with the highest pretreatment dose of cotinine (panel $\mathbf{c}$ ) or nornicotine (panels $\mathbf{f}$ and $\mathbf{i}$ ). Note that a higher dose range of nornicotine was used in experiment 6 vs. 5. Mean \pm SEM are shown. Within a given experiment, each rat $(n=12)$ was tested under all conditions. Asterisks are shown only for the top panels: $* p<0.05$ (i.e., trend), $* * p<0.01, * * * p<0.001$, nicotine vs. saline at a given dose of pretreatment drug. ${ }^{\#} p<0.05$ (i.e., trend), ${ }^{\# \#} p<0.01$, pretreatment drug alone vs. saline (paired $t$ tests, 2 -tailed alpha set at $1 \%$ )
Neither nicotine nor nornicotine significantly altered the percentage of flat or trill calls, and there was no significant drug interaction for either measure (Table 3; flat and trill, respectively: NOR $\mathrm{F}_{3,33}=2.20$ and $1.82, p=0.1070$ and 0.1673 ; NIC $\mathrm{F}_{1,11}=4.12$ and $0.14, p=0.0673$ and 0.7129 ; interactions $\mathrm{F}_{3,33}=0.26$ and $1.35, p=0.8413$ and 0.2751 ).

\section{Experiment 6: Nornicotine combined with nicotine (partial replication)}

LMA A higher nornicotine dose range was used than in experiment 5 (i.e., $0.3-3 \mathrm{mg} / \mathrm{kg}$ instead of $0.1-1 \mathrm{mg} / \mathrm{kg}$ ). Neither the locomotor stimulant effect of nicotine nor its interaction with nornicotine was time-dependent (Fig. 3h, i; 2-way and 3-way interactions, respectively: $\mathrm{F}_{11,99}=1.22, p=0.2923$ and $\mathrm{F}_{33,297}=$ $0.87, p=0.6596$ ). When tested alone, both nicotine and the highest nornicotine dose $(3 \mathrm{mg} / \mathrm{kg})$ significantly increased whole-session LMA (Fig. 3g; $t$ tests, respectively: $t_{9}=6.49$, $p=0.0001$ and $\left.t_{9}=3.52, p=0.0065\right)$, with the trend at nornicotine $1 \mathrm{mg} / \mathrm{kg}\left(t_{9}=2.27, p=0.0490\right)$. As in experiment 5 , nornicotine dose-dependently inhibited the locomotor stimulant effect of nicotine (NOR $\times \mathrm{NIC} \mathrm{F}_{3,27}=7.88, p=0.0006$ ); this interaction was significant at $3 \mathrm{mg} / \mathrm{kg}\left(\mathrm{F}_{1,9}=12.88, p=\right.$ $0.0058)$ but not at $1 \mathrm{mg} / \mathrm{kg}\left(\mathrm{F}_{1,9}=5.08, p=0.0507\right)$. Blockade appeared near-total at the highest nornicotine dose (residual nicotine effect: $t_{9}=2.38, p=0.0412$ ). 
Table $350-\mathrm{kHz}$ call rate, and prevalence of flat and trill 50-kHz call subtypes in rats treated with cotinine or nornicotine in combination with nicotine (experiments 4-6)

\begin{tabular}{|c|c|c|c|c|c|c|c|}
\hline & \multirow[t]{3}{*}{ COT (mg/kg) } & \multicolumn{2}{|c|}{$50-\mathrm{kHz}$ calls $/ 60 \mathrm{~min}$} & \multicolumn{2}{|l|}{ Percent flat } & \multicolumn{2}{|c|}{ Percent trill } \\
\hline & & \multicolumn{2}{|l|}{ Median (IQR) } & \multicolumn{2}{|c|}{ Mean \pm SEM } & \multicolumn{2}{|c|}{ Mean \pm SEM } \\
\hline & & Saline & Nicotine & Saline & Nicotine & Saline & Nicotine \\
\hline \multirow[t]{3}{*}{ Expt 4} & 0 & $61(20-370)$ & $23(5-145)$ & $16.0 \pm 4.0$ & $9.2 \pm 2.8$ & $41.7 \pm 7.6$ & $36.9 \pm 6.7$ \\
\hline & 0.3 & $89(31-467)$ & $28(6-113)$ & $10.4 \pm 1.5$ & $10.8 \pm 6.3$ & $47.8 \pm 4.6$ & $49.5 \pm 9.4$ \\
\hline & 3 & $98(42-205)$ & $14(4-50)$ & $13.0 \pm 4.2$ & $19.2 \pm 9.0$ & $48.0 \pm 5.8$ & $33.7 \pm 10.6$ \\
\hline \multirow[t]{5}{*}{ Expt 5} & NOR $(\mathrm{mg} / \mathrm{kg})$ & Saline & Nicotine & Saline & Nicotine & Saline & Nicotine \\
\hline & 0 & $98(36-269)$ & $47(11-150)$ & $29.2 \pm 4.9$ & $25.6 \pm 5.5$ & $25.7 \pm 4.2$ & $16.3 \pm 5.0$ \\
\hline & 0.1 & $115(40-163)$ & $49(29-315)$ & $25.5 \pm 3.5$ & $19.4 \pm 5.2$ & $24.4 \pm 4.8$ & $31.6 \pm 5.6$ \\
\hline & 0.3 & $127(34-184)$ & $159(43-378)$ & $23.8 \pm 4.5$ & $13.3 \pm 3.9$ & $29.4 \pm 5.2$ & $32.7 \pm 5.8$ \\
\hline & 1 & $123(37-224)$ & $146(41-223)$ & $20.3 \pm 4.1$ & $15.7 \pm 3.5$ & $30.1 \pm 6.2$ & $32.5 \pm 5.1$ \\
\hline \multirow[t]{5}{*}{ Expt 6} & $\mathrm{NOR}(\mathrm{mg} / \mathrm{kg})$ & Saline & Nicotine & Saline & Nicotine & Saline & Nicotine \\
\hline & 0 & $73(13-607)$ & $60(9-130)$ & - & - & - & - \\
\hline & 0.3 & $194(46-441)$ & $128(15-353)$ & - & - & - & - \\
\hline & 1 & $156(12-344)$ & $118(32-360)$ & - & - & - & - \\
\hline & 3 & $99(32-282)$ & $47(5-407)$ & - & - & - & - \\
\hline
\end{tabular}

The 50-kHz call rate is expressed as median and interquartile range (IQR). The prevalence of flat or trill calls is expressed as a percentage of all $50-\mathrm{kHz}$ calls emitted. COT, cotinine; NOR, nornicotine. $n=11-12,12$ and 9-10 rats (experiments 4-6, respectively)

50-kHz USVs The call rate (Table 3) was not significantly altered by either drug when given alone (nicotine and nornicotine, respectively: Wilcoxon $Z=1.58, p=0.1282$; Friedman $\left.Q_{3}=5.18, p=0.1590\right)$. Furthermore, no nornicotine $\times$ nicotine interaction was detected, based on one-way ANOVA using nicotine-saline difference scores as the dependent variable $\left(\mathrm{F}_{3,24}=0.75, p=0.5275\right)$.

\section{Discussion}

Novel findings are as follows. In nicotine-experienced rats, acute challenge with locomotor stimulant doses of nicotine tended to reduce the $50-\mathrm{kHz}$ call rate and did not alter the relative prevalence of flat and trill calls. Nornicotine administration, which produced mild locomotor stimulation, decreased $50-\mathrm{kHz}$ call rate at the highest dose tested, while promoting flat calls over trill calls. Nornicotine also countered the locomotor stimulant effect of nicotine, including at some lower doses. In contrast, cotinine affected neither locomotor activity (LMA) nor any of the $50-\mathrm{kHz}$ call measures. Finally, no drugs evoked 22-kHz calls.

\section{Pharmacokinetic aspects}

In interpreting any high-dose effects of nornicotine or cotinine administration, two potential caveats must be considered: trace contamination by nicotine (see Goldberg et al. 1989;
Oliver et al. 2007; Takada et al. 1989), and in vivo conversion to nicotine. In the present study, cotinine was without detectable effect, which is consistent with reports that cotinine is not significantly converted to nicotine in adult rats (Crooks et al. 1997; Sepkovic et al. 1984). Behavioral effects observed after nornicotine administration are unlikely to reflect trace amounts of nicotine, for two reasons. First, nornicotine appeared only about 10 -fold less potent than nicotine, as shown in Fig. 1. Second, nornicotine was supplied as $98 \%$ pure, and its synthesis route did not include nicotine; accordingly, nicotine was undetectable by proton NMR (data supplied by Toronto Research Chemicals). Lastly, we are unaware of any reports indicating that nornicotine can be converted to nicotine in vivo.

Both cotinine and nornicotine would be expected to reach the brain quite rapidly after SC injection. Thus, brain cotinine levels have been reported to peak at 30-60 min after SC cotinine injection (Crooks et al. 1997). Although comparable data appear unavailable for administered nornicotine, behavioral effects are seen within 10-20 min of SC injection. By way of comparison, after SC injection of nicotine, brain cotinine and nornicotine levels reached half-maximal by 30 60 min (Ghosheh et al. 1999; Vieira-Brock et al. 2013). Extrapolating from literature reports, it is possible to estimate approximate peak plasma and brain concentrations of cotinine and nornicotine that would occur during behavioral test sessions, following injections of either our standard nicotine dose $(0.2 \mathrm{mg} / \mathrm{kg} \mathrm{SC})$ or cotinine. The following estimates are based 
on the assumption that concentrations are directly proportional to dose administered:

After nicotine injection, we estimate maximal plasma levels of around $20-60 \mathrm{ng} / \mathrm{ml}$ for cotinine (Craig et al. 2014; Turner 1975; Vieira-Brock et al. 2011) and 0.1-1.5 ng/ml for nornicotine (Craig et al. 2014; Ghosheh et al. 2001; Vieira-Brock et al. 2013). Corresponding values for brain tissue would be approximately $10-25 \mathrm{ng} / \mathrm{g}$ for cotinine (Ghosheh et al. 1999; Vieira-Brock et al. 2011) and 2.5-10 ng/g for nornicotine (Ghosheh et al. 1999; Vieira-Brock et al. 2013).

After cotinine administration, the wide dose range used $(0.03-3 \mathrm{mg} / \mathrm{kg} \mathrm{SC})$ would have provided estimated peak plasma cotinine levels ranging from 40 to $4000 \mathrm{ng} / \mathrm{ml}$ and peak brain cotinine levels of 25 to $2500 \mathrm{ng} / \mathrm{g}$ ( $\mathrm{Li}$ et al. 2012; Terry et al. 2012). On this basis, our $0.2 \mathrm{mg} / \mathrm{kg}$ nicotine dose could be expected to produce cotinine levels corresponding to the lowest tested dose of cotinine.

For nornicotine administration, there appear to be no relevant published studies on which to base an estimate.

\section{Effects of drugs administered alone on locomotor activity}

In the present study, all rats first received home cage injections of nicotine to render them tolerant to the locomotor depressant effects of the drug. As expected, the acute locomotor stimulant effect of nicotine was detected at $0.1-0.4 \mathrm{mg} / \mathrm{kg}$ and the doseresponse relation was monotonic (Clarke and Kumar 1983b; Stolerman et al. 1995). Under the same conditions, cotinine did not detectably alter LMA. To our knowledge, acute locomotor effects of cotinine have only been reported in drugnaive rats, with only equivocal signs of locomotor depression (Marusich et al. 2017; Wiley et al. 2015).

Nornicotine acutely increased LMA, albeit within a narrow dose range (i.e., $1-3 \mathrm{mg} / \mathrm{kg}$ ), with an inverted-U dose-response relationship. These results appear consistent with previous reports suggesting that nornicotine acutely stimulates LMA in rats that have been subchronically treated with either nicotine (Stolerman et al. 1995) or nornicotine (Dwoskin et al. 1999a; Green et al. 2002; Stolerman et al. 1995). Although actions of nornicotine show some stereoselectivity (Dwoskin et al. 1999a; Green et al. 2001; Risner et al. 1988), the locomotor effects we observed using racemic nornicotine are in broad agreement with earlier findings obtained with either the racemate (Green et al. 2002), or the $\mathrm{R}(+)$ - isomer (Stolerman et al. 1995), or each isomer individually (Dwoskin et al. 1999a).

\section{Effects of drugs alone on call rate and call profile}

The absence of nicotine-induced $22-\mathrm{kHz}$ calls in our experiments is consistent with two literature reports (Simola et al.
2012; Simola et al. 2014), but runs counter to a third report in which spectrographically complex $22-\mathrm{kHz}$ vocalizations were observed after nicotine administration (Swalve et al. 2016). In previous work, the $50-k H z$ call rate tended to be reduced by acute nicotine administration in drug-naive rats (Simola et al. 2012; Simola et al. 2014; Swalve et al. 2016), whereas after repeated nicotine testing, the drug either did not significantly alter the call rate (Simola et al. 2014) or increased it (Swalve et al. 2016). In our nicotine-experienced rats, nicotine instead tended to decrease the $50-\mathrm{kHz}$ call rate, although statistical significance (with the alpha level set at $1 \%$ ) was reached in only 3 of the 6 experiments. The finding that nicotine concurrently reduced the $50-\mathrm{kHz}$ call rate while increasing LMA adds to evidence that these two measures can be dissociated (Burke et al. 2017; Engelhardt et al. 2017; Laplagne and Elias 2016; Wright et al. 2012a).

Here, we describe the acute effects of nicotine on the full range of $50-\mathrm{kHz}$ call subtypes identified by Wright et al. (2010). This level of detail was previously available only in nicotine-naive animals (Simola et al. 2012), as reports in nicotine-experienced rats were limited to trill calls (Simola et al. 2014) or to composite, multistep and upward ramp subtypes (Swalve et al. 2016). The low call rates occurring in these previous studies could potentially have obscured effects on call subtype prevalence, whereas in the present study, the majority (i.e., 93\%) of test sessions yielded enough $50-\mathrm{kHz}$ calls to derive a call profile with reasonable confidence.

Although nicotine decreased the $50-\mathrm{kHz}$ call rate, it did not appear to alter the prevalence of any call subtype; in particular, it left unchanged the relative proportions of flat and trill calls subtypes. When administered to human subjects, nicotine produces both positive and negative subjective effects and is at best only mildly euphoriant unless administered in a high dose as a rapid intravenous bolus (Dar et al. 2007; Kalman 2002). In contrast, drugs that are strongly euphoriant in humans (i.e., amphetamine, cocaine, and morphine) have all been found to promote trill calls over flat $50-\mathrm{kHz}$ calls (Best et al. 2017; Pereira et al. 2014; Wright et al. 2012b; Wright et al. 2010), and the opposite shift has been seen during acute morphine withdrawal (Lin et al. 2018). Hence, our findings support the proposal that trill calls, either considered alone or in relation to flat calls, distinguish positive vs. negative affect (Best et al. 2017; Lin et al. 2018; Wright et al. 2012b; Wright et al. 2010). As such, 50-kHz calls may prove useful in modeling affective disorders that occur in human subjects (Simola and Granon 2018).

Among nicotine metabolites, only cotinine appears to have been studied for its subjective effects in human subjects. In this context, cotinine was administered during tobacco abstinence (Benowitz et al. 1983; Hatsukami et al. 1998; Keenan et al. 1994), resulting in increased restlessness and anxiety in one study (Keenan et al. 1994). The effects of these drugs on rodent USV emission have not been previously reported. 
Here, nornicotine exerted significant effects at the highest dose tested $(10 \mathrm{mg} / \mathrm{kg})$, reducing the $50-\mathrm{kHz}$ call rate while increasing the proportion of flat calls relative to trills (Fig. 2, panel $\mathrm{m}$ vs. $\mathrm{r}$ ). This call profile shift suggests that high-dose nornicotine may be aversive, but whether nornicotine also produces a conditioned place or taste aversion appears unreported. Cotinine is reportedly neutral in the conditioned place preference/aversion assay (Fudala and Iwamoto 1986; Marusich et al. 2017), so its lack of effect on call profile (present study) is perhaps to be expected.

\section{Drug interactions with nicotine}

Since we were primarily attempting to detect possible inhibitory, nAChR-desensitizing, effects of cotinine and nornicotine (experiments 5-6), we chose a nicotine test dose $(0.2 \mathrm{mg} / \mathrm{kg}$ $\mathrm{SC}$ ) that robustly increased LMA. This dose was likely nearmaximal in terms of nicotine-induced locomotor stimulation (Clarke and Kumar 1983a; Clarke and Kumar 1983b; Stolerman et al. 1995), making it sub-optimal for detecting potential synergistic effects between the drugs. More specifically, if cotinine or nornicotine had rendered nicotine more potent (i.e., shifting the nicotine dose-response curve to the left), the resultant increase in nicotine-induced locomotion might have been too small to detect, even with a repeated measures design. If, instead, either pretreatment drug had made nicotine more efficacious (upward curve shift), there would be no such ceiling effect since nicotine, when administered alone, is only a weak locomotor stimulant.

In experiment 4 , acute cotinine pretreatment did not detectably alter LMA when given alone, nor did it significantly alter nicotine-induced locomotion. Although cotinine has been reported to increase nicotine-induced locomotion in rats (Clemens et al. 2009), it should be noted that in the latter study the possible effects of cotinine alone were apparently not controlled for. To our knowledge, the effect of acute nornicotine pretreatment has been tested against only two in vivo effects of nicotine: cue properties and reinforcing effects. The nicotine cue, tested in mice, was not significantly attenuated by nornicotine (Caine et al. 2014), whereas nornicotine pretreatment did reduce intravenous nicotine self-administration in rats (Caine et al. 2014; Green et al. 2000; Stairs et al. 2007). In the latter case, however, it is unclear whether nornicotine inhibited, or substituted for, a reinforcing effect of nicotine, and interpretation is further complicated by the finding that nornicotine markedly reduced sucrose-reinforced responding in one study (Stairs et al. 2007).

To our knowledge, only one LMA study has previously investigated interactions between nornicotine and nicotine (Dwoskin et al. 1999a). In this previous report, nornicotine pretreatment comprised multiple injections spread over several days, ending $48 \mathrm{~h}$ before the nicotine challenge. In the present study, in contrast, each nornicotine pretreatment comprised a single injection given $30 \mathrm{~min}$ in advance of nicotine. The latter pretreatment resulted in a dose-dependent inhibition of nicotineinduced locomotion, with a near-total block occurring at the highest nornicotine dose $(3 \mathrm{mg} / \mathrm{kg})$. Importantly, this interaction was not due to a ceiling effect, since after nicotine challenge the rats showed only moderate locomotor stimulation, for example, less than would be seen after administration of amphetamine (Louis and Clarke 1998; Simola et al. 2014).

In summary, our findings indicate that nornicotine can inhibit nicotine's ability to activate behaviorally relevant nAChRs, which possibly include $\alpha 4 \beta 2 *$ isoforms (Stolerman et al. 1997). Potential mechanisms include nAChR desensitization (see Introduction for references), or else partial agonism by nornicotine, as identified on a range of recombinant nAChR subtypes (Papke et al. 2007).

\section{Possible relation to tobacco smoking}

In experiment 1, a nicotine dose range was chosen so as to bracket the range of plasma nicotine concentrations seen in typical habitual smokers. In subsequent experiments, a dose of $0.2 \mathrm{mg} / \mathrm{kg}$ was used, expected to produce peak within-session blood levels of around $50 \mathrm{ng} / \mathrm{ml}$, compared with typical trough (i.e., between-cigarette) venous nicotine concentrations of $15-20 \mathrm{ng} / \mathrm{ml}$ in daily smokers (see Constantin and Clarke 2018).

It has been suggested that, in tobacco smokers, nornicotine and cotinine potentially achieve brain levels sufficient to activate some nAChR populations (Crooks and Dwoskin 1997; Ghosheh et al. 1999; Ghosheh et al. 2001; Miksys et al. 2000). Although the present study revealed only high-dose effects of nornicotine, these effects are conceivably of relevance to tobacco smoking, as follows. Although plasma levels of nornicotine are low in smokers $(\sim 2 \mathrm{ng} / \mathrm{ml}$ or $\sim$ $0.01 \mu \mathrm{M}$ )(Earla et al. 2014; Moyer et al. 2002), rodent studies indicate that brain nornicotine levels may be considerably higher. Thus, in adult rats, nornicotine persisted in the brain much longer than nicotine itself (Ghosheh et al. 1999) and accumulated further during chronic nicotine administration, with some nornicotine potentially formed locally in the brain (Ghosheh et al. 2001).

\section{Study limitations}

The main study limitations are as follows. First, without consistent nicotine effects on USV emission, only the drug's locomotor stimulant effect could be used to evaluate interactions with nornicotine and cotinine; the use of a single behavioral measure clearly does not reflect the diversity of nicotinic receptors in the CNS. Second, animals received multiple home cage injections of nicotine before the start of behavioral 
testing. This is a common procedure for inducing tolerance to the drug's depressant effects, but potentially reduces generalizability. Related to this, home cage nicotine pretreatment would likely have increased the density of brain nAChRs, but it is unclear to what extent this additional receptor pool would have been functional (Picciotto et al. 2008; Wu and Lukas 2011). Third, cotinine and nornicotine are both metabolized further in smokers (Hukkanen et al. 2005), and if their downstream metabolites are centrally active, they may not have had time to form during the 60-min test sessions. Fourth, as indicated above, our test dose of nicotine was not optimal for detecting possible synergistic effects. Lastly, the exclusive use of male rats leaves open the possibility of sex differences.

\section{Conclusion}

The present findings indicate that nornicotine administration can result in nicotine-opposing effects in vivo, as reported in vitro. At present, any possible relevance to tobacco smoking is unclear. Given that nicotine is at best only weakly euphoriant, its lack of detectable effect on ultrasonic call profiles supports the use of trill vs. flat call prevalence as a potential marker of affect.

Acknowledgments We wish to thank Lucas Marques and Adithi Sundarakrishnan for providing comments on the manuscript.

Funding information This study was supported by a Natural Science and Engineering Research Council of Canada (NSERC) discovery grant (155055, to P.B.S.C). Y.W. was supported by a McGill University Faculty of Medicine BSc/MSc fast-track award. P.B.S.C. is a member of the Center for Studies in Behavioral Neurobiology at Concordia University, Montreal.

Compliance with ethical standards All experiments comply with the current laws of Canada. All research procedures were reviewed and approved by the McGill Animal Care Committee in accordance with the guidelines of the Canadian Council on Animal Care.

Conflict of Interest The authors declare that they have no conflict of interest.

\section{References}

Bardo MT, Green TA, Crooks PA, Dwoskin LP (1999) Nornicotine is self-administered intravenously by rats. Psychopharmacology 146 : 290-296

Benowitz NL, Jacob P III (1994) Metabolism of nicotine to cotinine studied by a dual stable isotope method. Clin Pharmacol Ther 56: 483-493

Benowitz NL, Jacob P III, Fong I, Gupta S (1994) Nicotine metabolic profile in man: comparison of cigarette smoking and transdermal nicotine. J Pharmacol Exp Ther 268:296-303

Benowitz NL, Kuyt F, Jacob P, Jones RT, Osman AL (1983) Cotinine disposition and effects. Clin Pharmacol Ther 34:604-611
Best LM, Zhao LL, Scardochio T, Clarke PB (2017) Effects of repeated morphine on ultrasonic vocalizations in adult rats: increased $50-\mathrm{kHz}$ call rate and altered subtype profile. Psychopharmacology 234:155165

Briggs CA, McKenna DG (1998) Activation and inhibition of the human a7 nicotinic acetylcholine receptor by agonists. Neuropharmacology 37:1095-1102

Brudzynski SM (2015) Pharmacology of ultrasonic vocalizations in adult rats: significance, call classification and neural substrate. Curr Neuropharmacol 13:180-192

Buccafusco JJ, Terry AV (2003) The potential role of cotinine in the cognitive and neuroprotective actions of nicotine. Life Sci 72: 2931-2942

Burke CJ, Kisko TM, Swiftwolfe H, Pellis SM, Euston DR (2017) Specific $50-\mathrm{kHz}$ vocalizations are tightly linked to particular types of behavior in juvenile rats anticipating play. PLoS One 12: e0175841

Caine SB, Collins GT, Thomsen M, Wright C, Lanier RK, Mello NK (2014) Nicotine-like behavioral effects of the minor tobacco alkaloids nornicotine, anabasine, and anatabine in male rodents. Exp Clin Psychopharmacol 22:9-22

Clarke PBS, Kumar R (1983a) Characterization of the locomotor stimulant action of nicotine in tolerant rats. Br J Pharmacol 80:587-594

Clarke PBS, Kumar R (1983b) The effects of nicotine on locomotor activity in non-tolerant and tolerant rats. Br J Pharmacol 78:329-337

Clemens KJ, Caille S, Stinus L, Cador M (2009) The addition of five minor tobacco alkaloids increases nicotine-induced hyperactivity, sensitization and intravenous self-administration in rats. Int $\mathrm{J}$ Neuropsychopharmacol 15:1-12

Constantin A, Clarke PBS (2018) Reinforcement enhancement by nicotine in adult rats: behavioral selectivity and relation to mode of delivery and blood nicotine levels. Psychopharmacology 235:641650

Craig EL, Zhao B, Cui JZ, Novalen M, Miksys S, Tyndale RF (2014) Nicotine pharmacokinetics in rats is altered as a function of age, impacting the interpretation of animal model data. Drug Metab Dispos 42:1447-1455

Crooks PA, Dwoskin LP (1997) Contribution of CNS nicotine metabolites to the neuropharmacological effects of nicotine and tobacco smoking. Biochem Pharmacol 54:743-753

Crooks PA, Li M, Dwoskin LP (1997) Metabolites of nicotine in rat brain after peripheral nicotine administration. Cotinine, nornicotine, and norcotinine. Drug Metab Dispos 25:47-54

Dar R, Kaplan R, Shaham L, Frenk H (2007) Euphoriant effects of nicotine in smokers: fact or artifact? Psychopharmacology 191:203210

Dwoskin LP, Crooks PA, Teng LH, Green TA, Bardo MT (1999a) Acute and chronic effects of nornicotine on locomotor activity in rats: altered response to nicotine. Psychopharmacology 145:442-451

Dwoskin LP, Teng L, Buxton ST, Crooks PA (1999b) (S)-(-)-cotinine, the major brain metabolite of nicotine, stimulates nicotinic receptors to evoke $[3 \mathrm{H}]$ dopamine release from rat striatal slices in a calciumdependent manner. J Pharmacol Exp Ther 288:905-911

Dwoskin LP, Teng L, Buxton ST, Ravard A, Deo N, Crooks PA (1995) Minor alkaloids of tobacco release $\left[{ }^{3} \mathrm{H}\right]$ dopamine from superfused rat striatal slices. Eur J Pharmacol 276:195-199

Dwoskin LP, Teng LH, Crooks PA (2001) Nornicotine, a nicotine metabolite and tobacco alkaloid: desensitization of nicotinic receptorstimulated dopamine release from rat striatum. Eur J Pharmacol 428:69-79

Earla R, Ande A, McArthur C, Kumar A, Kumar S (2014) Enhanced nicotine metabolism in HIV-1-positive smokers compared with HIV-negative smokers: simultaneous determination of nicotine and its four metabolites in their plasma using a simple and sensitive electrospray ionization liquid chromatography-tandem mass spectrometry technique. Drug Metab Dispos 42:282-293 
Engelhardt KA, Fuchs E, Schwarting RK, Wohr M (2017) Effects of amphetamine on pro-social ultrasonic communication in juvenile rats: implications for mania models. Eur Neuropsychopharmacol 27:261-273

Fudala PJ, Iwamoto ET (1986) Further studies on nicotine-induced conditioned place preference in the rat. Pharmacol Biochem Behav 25: 1041-1049

Ghosheh O, Dwoskin LP, Li WK, Crooks PA (1999) Residence times and half-lives of nicotine metabolites in rat brain after acute peripheral administration of [2'-(14)C]nicotine. Drug Metab Dispos 27:14481455

Ghosheh OA, Dwoskin LP, Miller DK, Crooks PA (2001) Accumulation of nicotine and its metabolites in rat brain after intermittent or continuous peripheral administration of [2'- (14)C]nicotine. Drug Metab Dispos 29:645-651

Goldberg SR, Risner ME, Stolerman IP, Reavill C, Garcha HS (1989) Nicotine and some related compounds: effects on schedulecontrolled behaviour and discriminative properties in rats. Psychopharmacology 97:295-302

Green TA, Brown RW, Phillips SB, Dwoskin LP, Bardo MT (2002) Locomotor stimulant effects of nornicotine: role of dopamine. Pharmacol Biochem Behav 74:87-94

Green TA, Crooks PA, Bardo MT, Dwoskin LP (2001) Contributory role for nornicotine in nicotine neuropharmacology: nornicotine-evoked $[3 \mathrm{H}]$ dopamine overflow from rat nucleus accumbens slices. Biochem Pharmacol 62:1597-1603

Green TA, Phillips SB, Crooks PA, Dwoskin LP, Bardo MT (2000) Nornicotine pretreatment decreases intravenous nicotine selfadministration in rats. Psychopharmacology 152:289-294

Hatsukami D, Pentel PR, Jensen J, Nelson D, Allen SS, Goldman A, Rafael D (1998) Cotinine: effects with and without nicotine. Psychopharmacology 135:141-150

Hukkanen J, Jacob P III, Benowitz NL (2005) Metabolism and disposition kinetics of nicotine. Pharmacol Rev 57:79-115

Kalman D (2002) The subjective effects of nicotine: methodological issues, a review of experimental studies, and recommendations for future research. Nicotine Tob Res 4:25-70

Keenan RM, Hatsukami DK, Pentel PR, Thompson TN, Grillo MA (1994) Pharmacodynamic effects of cotinine in abstinent cigarette smokers. Clin Pharmacol Ther 55:581-590

Kyerematen GA, Morgan M, Warner G, Martin LF, Vesell ES (1990a) Metabolism of nicotine by hepatocytes. Biochem Pharmacol 40: 1747-1756

Kyerematen GA, Morgan ML, Chattopadhyay B, DeBethizy JD, Vesell ES (1990b) Disposition of nicotine and eight metabolites in smokers and nonsmokers: identification in smokers of two metabolites that are longer lived than cotinine. Clinical Pharmacology \& Therapeutics 48:641-651

Kyerematen GA, Vesell ES (1991) Metabolism of nicotine. Drug Metab Rev 23:3-41

Laplagne DA, Elias CM (2016) Rats synchronise locomotion with ultrasonic vocalizations at the subsecond time scale. Front Behav Neurosci 10:184

Li P, Beck WD, Callahan PM, Terry AV, Bartlett MG (2012) Quantitation of cotinine and its metabolites in rat plasma and brain tissue by hydrophilic interaction chromatography tandem mass spectrometry (HILIC-MS/MS). J Chromatogr B Analyt Technol Biomed Life Sci 907:117-125

Lin YC, Zhao LL, Clarke PBS (2018) Effects of acute morphine withdrawal on ultrasonic vocalizations in adult rats: unchanged $50-\mathrm{kHz}$ call rate and altered subtype profile. Psychopharmacology 235: 1945-1953

Liu B, Chen C, Wu D, Su Q (2008) Enantiomeric analysis of anatabine, nornicotine and anabasine in commercial tobacco by multidimensional gas chromatography and mass spectrometry. J Chromatogr B Analyt Technol Biomed Life Sci 865:13-17
Louis M, Clarke PBS (1998) Effect of ventral tegmental 6hydroxydopamine lesions on the locomotor stimulant action of nicotine in rats. Neuropharmacology 37:1503-1513

Lu Y, Grady S, Marks MJ, Picciotto M, Changeux JP, Collins AC (1998) Pharmacological characterization of nicotinic receptor-stimulated GABA release from mouse brain synaptosomes. J Pharmacol Exp Ther 287:648-657

Lu Y, Marks MJ, Collins AC (1999) Desensitization of nicotinic agonistinduced $[3 \mathrm{H}]$ gamma-aminobutyric acid release from mouse brain synaptosomes is produced by subactivating concentrations of agonists. J Pharmacol Exp Ther 291:1127-1134

Marusich JA, Darna M, Wilson AG, Denehy ED, Ebben A, Deaciuc AG, Dwoskin LP, Bardo MT, Lefever TW, Wiley JL, Reissig CJ, Jackson KJ (2017) Tobacco's minor alkaloids: effects on place conditioning and nucleus accumbens dopamine release in adult and adolescent rats. Eur J Pharmacol 814:196-206

Miksys S, Hoffmann E, Tyndale RF (2000) Regional and cellular induction of nicotine-metabolizing CYP2B1 in rat brain by chronic nicotine treatment. Biochem Pharmacol 59:1501-1511

Moyer TP, Charlson JR, Enger RJ, Dale LC, Ebbert JO, Schroeder DR, Hurt RD (2002) Simultaneous analysis of nicotine, nicotine metabolites, and tobacco alkaloids in serum or urine by tandem mass spectrometry, with clinically relevant metabolic profiles. Clin Chem 48:1460-1471

Oliver JL, Pashmi G, Barnett P, Mettens P, Biemans R, Monteyne P, Palmantier R, Gallagher T, Ramaya S, Wonnacott S (2007) Development of an anti-cotinine vaccine to potentiate nicotinebased smoking cessation strategies. Vaccine 25:7354-7362

Papke RL, Dwoskin LP, Crooks PA (2007) The pharmacological activity of nicotine and nornicotine on nAChRs subtypes: relevance to nicotine dependence and drug discovery. J Neurochem 101:160-167

Pereira M, Andreatini R, Schwarting RK, Brenes JC (2014) Amphetamine-induced appetitive $50-\mathrm{kHz}$ calls in rats: a marker of affect in mania? Psychopharmacology 231:2567-2577

Picciotto MR, Addy NA, Mineur YS, Brunzell DH (2008) It is not "either/or": activation and desensitization of nicotinic acetylcholine receptors both contribute to behaviors related to nicotine addiction and mood. Prog Neurobiol 84:329-343

Risner ME, Cone EJ, Benowitz NL, Jacob P (1988) Effects of the stereoisomers of nicotine and nornicotine on schedule-controlled responding and physiological parameters of dogs. J Pharmacol Exp Ther 244:807-813

Rollema H, Hurst RS (2018) The contribution of agonist and antagonist activities of alpha4beta $2 *$ nAChR ligands to smoking cessation efficacy: a quantitative analysis of literature data. Psychopharmacology 235:2479-2505

Sepkovic DW, Haley NJ, Axelrad CM, LaVoie EJ (1984) Thyroid hormone concentrations in rats after chronic nicotine metabolite administration. Proc Soc Exp Biol Med 177:412-416

Simola N, Brudzynski SM (2018) Rat 50-kHz ultrasonic vocalizations as a tool in studying neurochemical mechanisms that regulate positive emotional states. J Neurosci Methods 310:33-44

Simola N, Fenu S, Costa G, Pinna A, Plumitallo A, Morelli M (2012) Pharmacological characterization of $50-\mathrm{kHz}$ ultrasonic vocalizations in rats: comparison of the effects of different psychoactive drugs and relevance in drug-induced reward. Neuropharmacology 63:224-234

Simola N, Frau L, Plumitallo A, Morelli M (2014) Direct and long-lasting effects elicited by repeated drug administration on $50-\mathrm{kHz}$ ultrasonic vocalizations are regulated differently: implications for the study of the affective properties of drugs of abuse. Int J Neuropsychopharmacol 17:429-441

Simola N, Granon S (2018) Ultrasonic vocalizations as a tool in studying emotional states in rodent models of social behavior and brain disease. Neuropharmacology

Stairs DJ, Neugebauer NM, Wei X, Boustany C, Hojahmat M, Cassis LA, Crooks PA, Dwoskin LP, Bardo MT (2007) Effects of nornicotine 
enantiomers on intravenous $\mathrm{S}(-)$-nicotine self-administration and cardiovascular function in rats. Psychopharmacology 190:145-155

Stolerman IP, Chandler CJ, Garcha HS, Newton JM (1997) Selective antagonism of behavioural effects of nicotine by dihydro-berythroidine in rats. Psychopharmacology 129:390-397

Stolerman IP, Garcha HS, Mirza NR (1995) Dissociations between the locomotor stimulant and depressant effects of nicotinic agonists in rats. Psychopharmacology 117:430-437

Swalve N, Mulholland MM, Li M (2019) Alterations of acoustic features of $50 \mathrm{kHz}$ vocalizations by nicotine and phencyclidine in rats. Behav Pharmacol 30:446-451

Swalve N, Mulholland MM, Schulz TD, Li M (2016) Effects of the phencyclidine model of schizophrenia and nicotine on total and categorized ultrasonic vocalizations in rats. Behav Pharmacol 27: $321-330$

Takada K, Swedberg MD, Goldberg SR, Katz JL (1989) Discriminative stimulus effects of intravenous 1-nicotine and nicotine analogs or metabolites in squirrel monkeys. Psychopharmacology 99:208-212

Teng LH, Crooks PA, Buxton ST, Dwoskin LP (1997) Nicotinic-receptor mediation of $\mathrm{S}(-)$ nornicotine-evoked $\left[{ }^{3} \mathrm{H}\right]$ overflow from rat striatal slices preloaded with $\left[{ }^{3} \mathrm{H}\right]$ dopamine. J Pharmacol Exp Ther 283: 778-787

Terry AV, Buccafusco JJ, Schade RF, Vandenhuerk L, Callahan PM, Beck WD, Hutchings EJ, Chapman JM, Li P, Bartlett MG (2012) The nicotine metabolite, cotinine, attenuates glutamate (NMDA) antagonist-related effects on the performance of the five choice serial reaction time task (5C-SRTT) in rats. Biochem Pharmacol 83: 941-951

Terry AV, Callahan PM, Bertrand D (2015) R-(+) and S-(-) isomers of cotinine augment cholinergic responses in vitro and in vivo. $\mathrm{J}$ Pharmacol Exp Ther 352:405-418

Turner DM (1975) Influence of route of administration on metabolism of [14C]nicotine in four species. Xenobiotica 5:553-561

Vainio PJ, Tornquist K, Tuominen RK (2000) Cotinine and nicotine inhibit each other's calcium responses in bovine chromaffin cells. Toxicol Appl Pharmacol 163:183-187
Vieira-Brock PL, Andrenyak DM, Nielsen SM, Fleckenstein AE, Wilkins DG (2013) Age-related differences in the disposition of nicotine and metabolites in rat brain and plasma. Nicotine Tob Res 15:18391848

Vieira-Brock PL, Miller EI, Nielsen SM, Fleckenstein AE, Wilkins DG (2011) Simultaneous quantification of nicotine and metabolites in rat brain by liquid chromatography-tandem mass spectrometry. J Chromatogr B Analyt Technol Biomed Life Sci 879:3465-3474

Wiley JL, Marusich JA, Thomas BF, Jackson KJ (2015) Determination of behaviorally effective tobacco constituent doses in rats. Nicotine Tob Res 17:368-371

Willadsen M, Best LM, Wohr M, Clarke PBS (2018) Effects of anxiogenic drugs on the emission of $22-$ and $50-\mathrm{kHz}$ ultrasonic vocalizations in adult rats. Psychopharmacology 235:2435-2445

Wohr M, Schwarting RK (2013) Affective communication in rodents: ultrasonic vocalizations as a tool for research on emotion and motivation. Cell Tissue Res 354:81-97

Wright JM, Deng L, Clarke PB (2012a) Failure of rewarding and locomotor stimulant doses of morphine to promote adult rat $50-\mathrm{kHz}$ ultrasonic vocalizations. Psychopharmacology 224:477-487

Wright JM, Dobosiewicz MR, Clarke PB (2012b) Alpha- and betaadrenergic receptors differentially modulate the emission of spontaneous and amphetamine induced $50-\mathrm{kHz}$ ultrasonic vocalizations in adult rats. Neuropsychopharmacology 37:808-821

Wright JM, Gourdon J, Clarke PBS (2010) Identification of multiple call categories within the rich repertoire of adult rat $50-\mathrm{kHz}$ ultrasonic vocalizations: effects of amphetamine and social context. Psychopharmacology 211:1-13

Wu J, Lukas RJ (2011) Naturally-expressed nicotinic acetylcholine receptor subtypes. Biochem Pharmacol 82:800-807

Publisher's note Springer Nature remains neutral with regard to jurisdictional claims in published maps and institutional affiliations. 